\title{
Migration and Differentiation of Canine Bone Marrow Stromal Cells Transplanted into the Developing Mouse Brain
}

\author{
Hiroaki KAMISHINA ${ }^{1) *}$, Jennifer A. CHEESEMAN ${ }^{1}$, James P. FARESE ${ }^{1)}$, Rowan J. MILNER ${ }^{1)}$ and Roger M. \\ CLEMMONS $^{1)}$ \\ ${ }^{1)}$ Department of Small Animal Clinical Sciences, College of Veterinary Medicine, University of Florida, Gainesville, FL, 32610-0126, \\ U.S.A.
}

(Received 11 August 2009/Accepted 24 October 2009/Published online in J-STAGE 1 December 2009)

\begin{abstract}
To evaluate whether canine bone marrow stromal cells (BMSCs) can migrate and adopt neural phenotypes in the developing mouse brain we transplanted fluorescently labeled BMSCs into the lateral ventricle of immunocompromised neonatal mice. Most fibroblasts, used as a control, and BMSCs isolated from adult dogs remained around the injection site and exhibited a spindle-shaped appearance. A small number of BMSCs from young dogs were found in the subventricular zone, rostral migratory stream, and olfactory bulbs, and retained expression of neuron marker. Our findings suggest that BMSCs isolated from adult dogs have limited ability of migration and differentiation toward neural cells in the developing brain. Bone marrow of young dogs may contain a primitive stem cell population with neural differentiation capacity.
\end{abstract}

KEY WORDS: bone marrow stromal cell, canine, central nervous system, differentiation.

J. Vet. Med. Sci. 72(3): 353-356, 2010

Neurotransplantation has generated tremendous attention as a potential therapeutic approach for disorders of the central nervous system (CNS). Neural stem cells [15, 17] and embryonic stem cells $[9,14]$ have been extensively studied and shown to ameliorate CNS diseases in experimental models of various CNS disorders. Cells and tissues derived from fetuses have been used to treat human patients with Parkinson's disease [11] and spinal cord injury (SCI) [21]. However, these cell/tissue types pose serious obstacles with respect to the harvesting of donor cells/tissues and the possibility of tumorigenesis. Transplantation of bone marrowderived cells may provide a viable alternative strategy. Bone marrow contains bone marrow stromal cells (BMSCs), nonhematopoietic cells that provide a bone marrow microenvironment and regulate hematopoiesis [4] and also serve as a stem cell reservoir for mesenchymal cells [16].

Perspectives on BMSCs for neurotransplantation have rapidly grown during the last decade, based on several reports on BMSC differentiation into neural phenotypes both in vitro $[19,22]$ and in vivo [1, 2]. Therapeutic benefits of BMSC transplantation have been repeatedly shown in experimental models of CNS injuries [13, 23]. Although functional recovery from CNS injury may not result solely from neural differentiation and cellular replacement by transplanted BMSCs, investigations of migratory and neural differentiation properties of BMSCs provide insights into their potentials in the treatment of CNS diseases and aid in refining the design of new clinical trials.

In the present study, we transplanted fluorescently

* Correspondence to: Kamishina, H., Division of Small Animal Internal Medicine, Department of Veterinary Medicine, Faculty of Agriculture, Iwate University, 3-18-8 Ueda, Morioka, Iwate 020-8550, Japan.

e-mail:kamicna@iwate-u.ac.jp labeled canine BMSCs into the lateral ventricle of immunocompromised neonatal mice. We wished to determine by immunohistochemistry whether canine BMSCs can migrate and adopt neural phenotypes in the developing mouse brain.

Preparation of canine BMSCs and fibroblasts: Bone marrow from four adult canine cadavers, obtained from a local animal shelter, was used to isolate and culture canine BMSCs. Exact ages of these dogs were unknown; however, we collected bone marrow from only those which had a complete set of adult teeth with minimum dental calculus deposition, thus meeting inclusion criteria for "young adults". Bone marrow was also collected from two young dog cadavers (estimated age between 3 to 5 months old) obtained from the local animal shelter. The use of these animals was approved by the Institutional Animal Care and Use Committee of University of Florida. In all animals, bone marrow was collected from a femur by flushing the medullary canal immediately after euthanasia. Mononucleated cells were isolated on a Ficoll (Ficoll-Paque, StemCell Technologies, Vancouver, Canada) density gradient, washed in PBS, and suspended in culture medium consisting of DMEM $(1 \mathrm{~g} / l$ glucose) supplemented with $10 \%$ fetal bovine serum (FBS) and antibiotics $(100 \mathrm{U} / \mathrm{m} l$ penicillin $\mathrm{G}$, $100 \mu \mathrm{g} / \mathrm{m} l$ streptomycin sulfate, and $0.25 \mu \mathrm{g} / \mathrm{m} l$ amphotericin B). Cell surface marker profiles, growth kinetics, and differentiation properties of isolated canine BMSCs have been described in our previous studies [6-8]. Canine skinderived third passage fibroblasts (Coriell Institute for Medical Research) were used for comparative purposes. Primary adherent BMSCs were grown until semiconfluency after which cells were trypsinized and labeled with the fluorescent carbocyanine dye, DiI (Invitrogen Corporation, Carlsbad, CA). Fluorescent labeling was performed according to a protocol of Laywell et al. [12] with modifications. 
Briefly, trypsinized BMSCs or fibroblasts were washed three times in PBS and resuspended in PBS containing DiI (final concentration, $40 \mu \mathrm{g} / \mathrm{m} l$ ). The cells were incubated in the DiI-containing PBS for $5 \mathrm{~min}$ at $37^{\circ} \mathrm{C}$ followed by 15 min at $4^{\circ} \mathrm{C}$ before being washed three times in PBS. DiI labeled BMSCs and fibroblasts were frozen at $-80^{\circ} \mathrm{C}$ until transplantation was performed.

Transplantation of canine BMSCs and fibroblasts into neonatal mouse brain: Postnatal day-2 immunocompro-

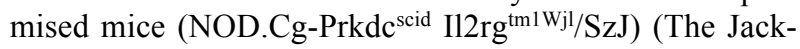
son Laboratory, Bar Harbor, ME, U.S.A.) were used as recipients $(n=29)$. On the day of transplantation, DiIlabeled BMSCs or fibroblasts were thawed, washed three times in PBS, and the cell number was determined. Cell suspensions were made in PBS $\left(2.0 \times 10^{5} / \mu l\right)$ and transferred on ice to the mouse facility. DiI-labeled BMSCs or fibroblasts were transplanted into the left lateral ventricle of postnatal day-2 immunocompromised mice as described previously [3]. Under hypothermic anesthesia, $2.0 \times 10^{5}$ cells in $1 \mu l$ of PBS were slowly injected into the left lateral ventricle, through a $30 \mathrm{G}$ needle attached to a $5 \mu$ l Hamilton syringe. Ten day post-transplantation, mice were euthanized with $\mathrm{CO}_{2}$ gas and transcardially perfused with $4 \%$ paraformaldehyde in PBS. The brains were excised, postfixed, and sectioned with a freezing microtome into $40 \mu \mathrm{M}$ sagittal or coronal slices for immunohistochemistry.

Immunohistochemistry to evaluate migration and differentiation of canine BMSCs: Immunohistochemical staining of free-floating brain slices were performed, using anti- $\beta$ IIItubulin (1:500) (Promega Corporation, Madison, WI, U.S.A.) and AlexaFluor 488-conjugated anti-NeuN (1:50) (Millipore, Billerica, MA, U.S.A.), and anti-GFAP (1:100) (Biosciences, Franklin Lakes, NJ, U.S.A.) antibodies. In order to assess the maturation of differentiated cells, $\beta$ III- tubulin and NeuN were used as early and mature neuronal markers, respectively. The cross-reactivity of these primary antibodies to canine cells has been confirmed by our preliminary experiment and previous study [7]. Brain slices were washed three times in PBS and permeabilized in $0.4 \%$ Triton X-100 in PBS for $30 \mathrm{~min}$ at $25^{\circ} \mathrm{C}$. Non-specific binding was blocked with a blocking solution $(3.0 \%$ normal goat serum in PBS) for $60 \mathrm{~min}$ at $25^{\circ} \mathrm{C}$. Brain slices were then incubated overnight at $4^{\circ} \mathrm{C}$ with the primary antibodies. The primary antibodies were removed, slices washed three times in PBS, and incubated for $60 \mathrm{~min}$ in dark at $25^{\circ} \mathrm{C}$ with secondary antibodies. The secondary antibodies were Cy 2 conjugated goat anti-mouse IgG1 (1:400) (Jackson ImmunoResearch Laboratories, Inc., West Grove, PA, U.S.A.) or IgG2b (1:200) (Jackson ImmunoResearch Laboratories, Inc., West Grove, PA, U.S.A.). Stained slices were observed under a fluorescent microscope (Zeiss Axioplan II, Carl Zeiss Microimaging Inc.) to evaluate engraftment and phenotypes of transplanted canine BMSCs.

Distribution and phenotypic fates of adult canine BMSCs and fibroblasts: Of 29 recipient mice, 27 survived the 10day survival period and were processed for analysis. Transplanted cells could be readily identified by the presence of DiI in the cytoplasm. In mice that received adult canine BMSCs $(n=17)$, most of the engrafted cells remained around the injection site, adhering to the wall of the lateral ventricle (Fig. 1A). Some cells were found in the underlying parenchyma of the thalamus and hippocampus; however, it was not possible to determine whether these cells had migrated into the parenchyma from the injection site or were directly injected into these locations. There were also cells sparsely dispersed in the cerebral cortex distant from the needle tract, which seemed to have migrated there instead of being directly injected. Additionally, a small number of cells were
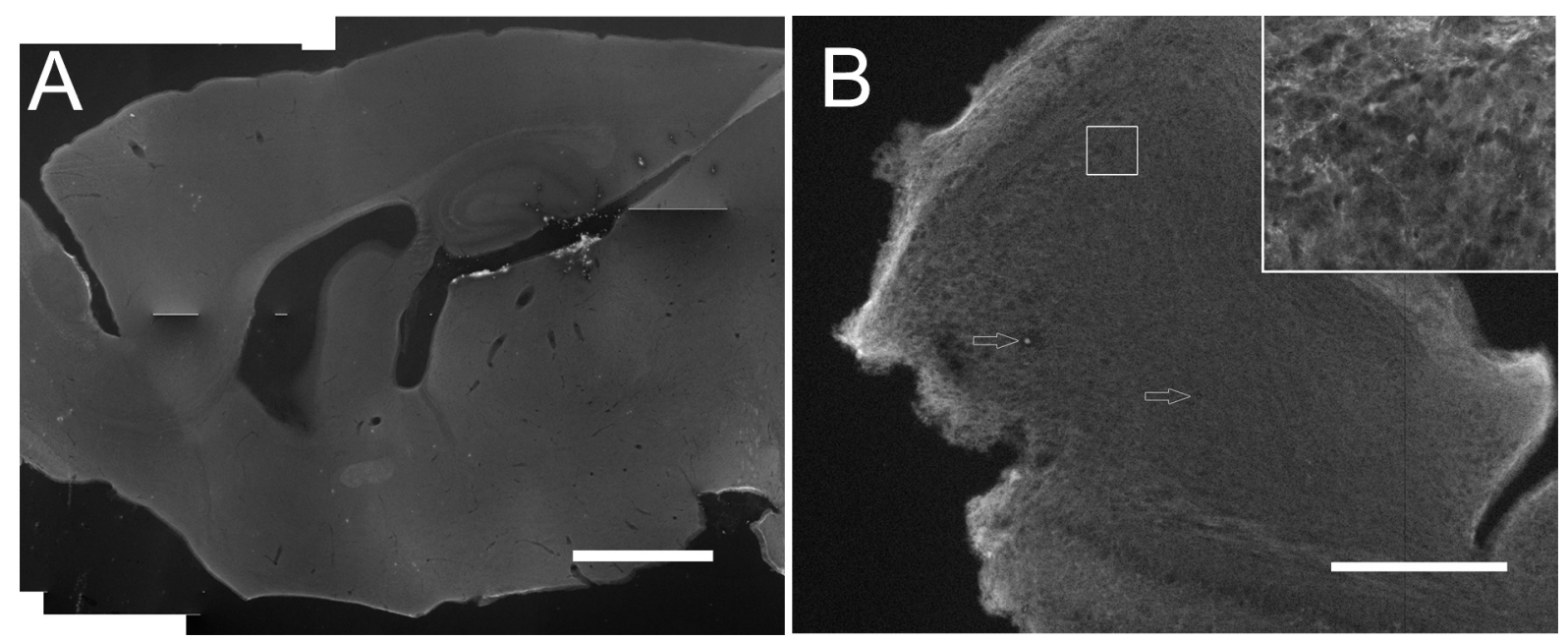

Fig. 1. Distribution of transplanted BMSCs. (A) Montage immunofluorescence photomicrograph of mouse brain with engrafted adult canine BMSCs. This sagittal section was stained with $\beta$ III-tubulin and visualized with Cy2 (green). Most of DiI-positive BMSCs (red) were located around the injection site along the wall of the lateral ventricle. Scale bar $=200 \mu \mathrm{m}$. (B) DiI-positive BMSCs isolated from young donors present in the olfactory bulb. A small number of DiI positive BMSCs were found in the olfactory bulb (arrows). Inset shows a higher magnification view of a BMSC in the boxed area. Scale bar=100 $\mu \mathrm{m}$. 

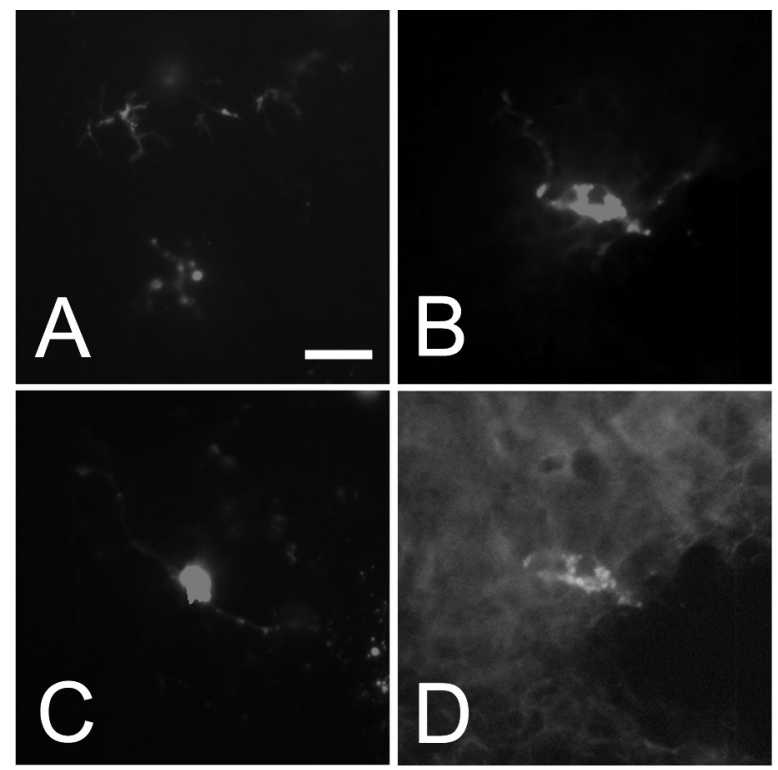

Fig. 2. Various morphologies of young BMSCs in the SVZ. Some cells located in the SVZ assumed process-bearing neuron-like (A) or bipolar neuron-like morphology (B). DiI positive BMSC seen in the SVZ (C) is immunopositive against $\beta$ III-tubulin (D). Scale bar $=20 \mu \mathrm{m}$.

widely distributed around the periphery of the brain, attaching to the pia matter but not penetrating into the brain parenchyma.

The majority of the engrafted adult BMSCs exhibited a spindle-shaped appearance similar to their in vitro characteristic morphology. A small population of cells that migrated into the parenchyma underlying the ventricle showed process-bearing morphology. However, immunohistochemistry showed that engrafted cells expressed neither neuron markers ( $\beta$ III-tubulin and NeuN) nor astrocyte marker (GFAP). Engrafted canine fibroblasts $(n=3)$ showed a similar tendency of distribution and phenotypic patterns to adult BMSCs.

Distribution and phenotypic fates of young canine $B M S C s$ : In mice $(\mathrm{n}=7)$ receiving BMSCs isolated from young donors, transplanted BMSCs demonstrated a different behavior from those observed with adult BMSCs and fibroblasts. Although most BMSCs of young donors remained around the injection site in the lateral ventricle, a small number of cells were located in the olfactory bulb and the rostral migratory stream (RMS), a known pathway of neuronal precursors migrating from the subventricular zone (SVZ) to the olfactory bulb (Fig 1B). These cells in the olfactory bulb and RMS were $\beta$ III-tubulin positive. In the SVZ, most of engrafted BMSCs exhibited typical fibroblastic morphology, but some cells assumed process-bearing neuron-like morphology (Fig. 2A and B). Immunostaining revealed that a significant number of BMSCs in the SVZ were $\beta$ III-tubulin positive (Fig. 2C and D). Expression of neither NeuN nor GFAP was found in any region containing
BMSCs. The results suggested that the transplanted cells did not undergo full maturation towards neuronal cells or glial cells.

Our data suggest that canine BMSCs isolated from adult canine bone marrow have limited ability of migration and differentiation toward neural cells in the developing mouse brain. Most of adult BMSCs remained around the injection site and retained spindle-shape appearance similar to their in vitro morphology. Some adult BMSCs were found in the SVZ; however, these cells expressed neither neuron- nor astrocyte-markers. In contrast, young canine BMSCs injected in the lateral ventricle penetrated into the SVZ and were integrated in the postnatal neurogenic pathway of the RMS/olfactory bulb system. Our observation that a small number of young canine BMSCs migrated to the olfactory bulb and retained $\beta$ III-tubulin expression suggested that these cells may possess neural differentiation capability. This finding also suggested that a population of young canine BMSCs may behave like neural precursor cells that contribute to postnatal neurogenesis.

Our observation of the migration and differentiation properties of young canine BMSCs was similar to those of previous studies in which murine BMSCs were engrafted into the lateral ventricle of the neonatal mouse brain $[3,10]$. We found that although most of BMSCs remained around the injection site, a small number of young canine BMSCs penetrated into the SVZ and assumed various morphologies resembling process-bearing neurons. Immunostaining suggested that some of these cells in the SVZ express neuronmarker $\beta$ III-tubulin. The SVZ forms adjacent to the lateral ventricle during embryogenesis and is known to contain multipotent neural stem cells. The SVZ is also the area of active neurogenesis in the postnatal and adult brain. Therefore, young canine BMSCs located in the SVZ may have responded to microenvironmental cues provided by the SVZ and differentiated toward the neuronal phenotype. However, the possibilities of cell fusion between transplanted BMSCs and endogenous neurons [20] or engulfment of transplanted cells by macrophages could not be entirely excluded and need further investigations.

It may simply be that bone marrow from young dogs contained a larger number of stem cells, which survived transplantation, than adult bone marrow. Alternatively, it could be that differentiated BMSCs were derived from a more primitive stem cell population present in the BMSC fraction of the young donors. The presence of a rare pluripotent stem cell population has been reported in adult mouse [5] and human [18] bone marrow and shown to have neural differentiation capacity. These cells can only be expanded at extremely low cell density on fibronectin and in the presence of leukemia inhibitory factor (LIF) and plateletderived growth factor (PDGF). Existence of a similar cell population in adult canine bone marrow remains unknown. As we utilized the standard culture condition (at standard cell density without growth factors) to prepare all BMSCs for transplantation, cells with multipotent differentiation properties might not have been expanded from the adult 
bone marrow sample. Thus, identification of cell populations with multipotential differentiation properties resident in canine bone marrow needs to be investigated.

ACKNOWLEDGMENTS. We thank Maggie Stoll and Harumi Kamishina for their help in processing brain tissues for immunohistochemistry. We also thank Ryan Fiske for his assistance in managing our immunocompromised mouse colony. This work was supported by the College of Veterinary Medicine, University of Florida Consolidated Faculty Research Development Award Grant.

\section{REFERENCES}

1. Arnhold, S., Klein, H., Klinz, F. J., Absenger, Y., Schmidt, A., Schinkothe, T., Brixius, K., Kozlowski, J., Desai, B., Bloch, W. and Addicks, K. 2006. Human bone marrow stroma cells display certain neural characteristics and integrate in the subventricular compartment after injection into the liquor system. Eur. J. Cell Biol. 85: 551-565.

2. Azizi, S. A., Stokes, D., Augelli, B. J., DiGirolamo, C. and Prockop, D. J. 1998. Engraftment and migration of human bone marrow stromal cells implanted in the brains of albino rats--similarities to astrocyte grafts. Proc. Natl. Acad. Sci. U.S. A. 95: 3908-3913.

3. Deng, J., Petersen, B. E., Steindler, D. A., Jorgensen, M. L. and Laywell, E. D. 2006. Mesenchymal stem cells spontaneously express neural proteins in culture and are neurogenic after transplantation. Stem Cells 24: 1054-1064.

4. Dormady, S. P., Bashayan, O., Dougherty, R., Zhang, X. M. and Basch, R. S. 2001. Immortalized multipotential mesenchymal cells and the hematopoietic microenvironment. J. Hematother. Stem Cell Res. 10: 125-140.

5. Jiang, Y., Jahagirdar, B. N., Reinhardt, R. L., Schwartz, R. E., Keene, C. D., Ortiz-Gonzalez, X. R., Reyes, M., Lenvik, T., Lund, T., Blackstad, M., Du, J., Aldrich, S., Lisberg, A., Low, W. C., Largaespada, D. A. and Verfaillie, C. M. 2002. Pluripotency of mesenchymal stem cells derived from adult marrow. Nature 418: 41-49.

6. Kamishina, H., Cheeseman, J. A. and Clemmons, R. M. 2008. Nestin-positive spheres derived from canine bone marrow stromal cells generate cells with early neuronal and glial phenotypic characteristics. In Vitro Cell Dev. Biol. Anim. 44: 140144.

7. Kamishina, H., Deng, J., Oji, T., Cheeseman, J. A. and Clemmons, R. M. 2006. Expression of neural markers on bone marrow-derived canine mesenchymal stem cells. Am. J. Vet. Res. 67: 1921-1928.

8. Kamishina, H., Farese, J. P., Storm, J. A., Cheeseman, J. A. and Clemmons, R. M. 2008. The frequency, growth kinetics, and osteogenic/adipogenic differentiation properties of canine bone marrow stromal cells. In Vitro Cell Dev. Biol. Anim. 44: $472-479$.

9. Keirstead, H. S., Nistor, G., Bernal, G., Totoiu, M., Cloutier, F., Sharp, K. and Steward, O. 2005. Human embryonic stem cell-derived oligodendrocyte progenitor cell transplants remyelinate and restore locomotion after spinal cord injury. J. Neurosci. 25: 4694-4705.

10. Kopen, G. C., Prockop, D. J. and Phinney, D. G. 1999. Marrow stromal cells migrate throughout forebrain and cerebellum, and they differentiate into astrocytes after injection into neonatal mouse brains. Proc. Natl. Acad. Sci. U.S.A. 96: 10711-10716.

11. Kordower, J. H., Freeman, T. B., Snow, B. J., Vingerhoets, F. J., Mufson, E. J., Sanberg, P. R., Hauser, R. A., Smith, D. A., Nauert, G. M., Perl, D. P. and et al. 1995. Neuropathological evidence of graft survival and striatal reinnervation after the transplantation of fetal mesencephalic tissue in a patient with Parkinson's disease. New Engl. J. Med. 332: 1118-1124.

12. Laywell, E. D., Friedman, P., Harrington, K., Robertson, J. T. and Steindler, D. A. 1996. Cell attachment to frozen sections of injured adult mouse brain: effects of tenascin antibody and lectin perturbation of wound-related extracellular matrix molecules. J. Neurosci. Methods 66: 99-108.

13. Lee, J., Kuroda, S., Shichinohe, H., Ikeda, J., Seki, T., Hida, K., Tada, M., Sawada, K. and Iwasaki, Y. 2003. Migration and differentiation of nuclear fluorescence-labeled bone marrow stromal cells after transplantation into cerebral infarct and spinal cord injury in mice. Neuropathology 23: 169-180.

14. Nistor, G. I., Totoiu, M. O., Haque, N., Carpenter, M. K. and Keirstead, H. S. 2005. Human embryonic stem cells differentiate into oligodendrocytes in high purity and myelinate after spinal cord transplantation. Glia 49: 385-396.

15. Ogawa, Y., Sawamoto, K., Miyata, T., Miyao, S., Watanabe, M., Nakamura, M., Bregman, B. S., Koike, M., Uchiyama, Y., Toyama, Y. and Okano, H. 2002. Transplantation of in vitroexpanded fetal neural progenitor cells results in neurogenesis and functional recovery after spinal cord contusion injury in adult rats. J. Neurosci. Res. 69: 925-933.

16. Pittenger, M. F., Mackay, A. M., Beck, S. C., Jaiswal, R. K., Douglas, R., Mosca, J. D., Moorman, M. A., Simonetti, D. W., Craig, S. and Marshak, D. R. 1999. Multilineage potential of adult human mesenchymal stem cells. Science 284: 143-147.

17. Pluchino, S., Quattrini, A., Brambilla, E., Gritti, A., Salani, G., Dina, G., Galli, R., Del Carro, U., Amadio, S., Bergami, A., Furlan, R., Comi, G., Vescovi, A. L. and Martino, G. 2003. Injection of adult neurospheres induces recovery in a chronic model of multiple sclerosis. Nature 422: 688-694.

18. Reyes, M., Lund, T., Lenvik, T., Aguiar, D., Koodie, L. and Verfaillie, C. M. 2001. Purification and ex vivo expansion of postnatal human marrow mesodermal progenitor cells. Blood 98: $2615-2625$.

19. Sanchez-Ramos, J., Song, S., Cardozo-Pelaez, F., Hazzi, C., Stedeford, T., Willing, A., Freeman, T. B., Saporta, S., Janssen, W., Patel, N., Cooper, D. R. and Sanberg, P. R. 2000. Adult bone marrow stromal cells differentiate into neural cells in vitro. Exp.Neurol. 164: 247-256.

20. Terada, N., Hamazaki, T., Oka, M., Hoki, M., Mastalerz, D. M., Nakano, Y., Meyer, E. M., Morel, L., Petersen, B. E. and Scott, E. W. 2002. Bone marrow cells adopt the phenotype of other cells by spontaneous cell fusion. Nature 416: 542-545.

21. Thompson, F. J., Reier, P. J., Uthman, B., Mott, S., Fessler, R. G., Behrman, A., Trimble, M., Anderson, D. K. and Wirth, E. D., 3rd 2001. Neurophysiological assessment of the feasibility and safety of neural tissue transplantation in patients with syringomyelia. J. Neurotrauma 18: 931-945.

22. Woodbury, D., Schwarz, E. J., Prockop, D. J. and Black, I. B. 2000. Adult rat and human bone marrow stromal cells differentiate into neurons. J. Neurosci. Res. 61: 364-370.

23. Wu, Q. Y., Li, J., Feng, Z. T. and Wang, T. H. 2007. Bone marrow stromal cells of transgenic mice can improve the cognitive ability of an Alzheimer's disease rat model. Neurosci. Lett. 417: 281-285. 